\title{
Pengaruh Servicescape dan Kualitas Komunikasi terhadap Loyalitas nasabah melalui Kepuasan nasabah sebagai variabel intervening (studi pada nasabah Bank Tabungan Pensiunan Nasional Kantor Cabang Yogyakarta)
}

\author{
Pricilia Sinta Sakinda ${ }^{1}$, Henny Welsa ${ }^{2}$, Muinah Fadhilah ${ }^{3}$ \\ Fakultas Ekonomi, Universitas Sarjanawiyata Tamansiswa Yogyakarta \\ Email: sintasknd95@gmail.com
}

\begin{abstract}
The purpose of this study was to examine direct and indirect effects of an integrated model of servicescape and communication quality upon customer loyalty, and considered customer satisfaction as intervening variable. This study used a causal design. The main data used in this study are primary data collected through the circulation of questionnaires to the respondents BTPN bank customers in Yogyakarta. The sampling technique using purposive sampling method to determine the sample based on the consideration of researchers. Data Analysis used Partial Least Square (PLS) yaitu SEM berbasis variance, dengan software SmartPLS. Based on the analysis it can be concluded that: the result of study supports the influence of servicescape to customer satisfaction, supports the influence of servicescape to customer loyalty, supports the influence of communication quality to customer satisfaction, supports the influence of communication quality to customer loyalty, supports the influence of customer satisfaction to customer loyalty, supports the influence of servicescape to customer loyalty through customer satisfaction, supports the influence of communication quality to customer loyalty through customer satisfaction.
\end{abstract}

\section{Keywords: Servicescape, Communication Quality, Customer Satisfaction, and Customer Loyalty.}

\section{PENDAHULUAN}

Bank Tabungan Pensiunan Nasional (BTPN) merupakan salah satu Bank Swasta yang bergerak di bidang perbankan nasional. Bank BTPN berusaha memprioritaskan kepuasan nasabahnya agar nasabah dapat melakukan pembelian ulang dengan meningkatkan kinerja setiap karyawannya. Dalam menjalankan misinya, yaitu Bank BTPN memberikan pelayanan prima kepada nasabah melalui jaringan kerja yang tersebar luas dengan meningkatkan kualitas sumber daya manusia, terutama pada karyawan yang menangani atau berhubungan langsung dengan nasabah agar pelayanan jasa yang diberikan kepada nasabah dapat optimal.

Servicescape bagi bank merupakan satu wujud yang dapat mempengaruhi perilaku dan respon nasabah terhadap jasa yang diberikan oleh pihak bank. Menurut Zeithaml dan Bitner (2013:283) pemahaman servicescape sangat penting bagi pemasar jasa, karena servicescape dapat memainkan beberapa peran sekaligus, yaitu sebagai package (mengemas), facilitator (fasilitas), socializer 
(membantu sosialisasi dan differentiator (pembeda). Dalam hal ini bank menggunakan lingkungan fisik sebagai salah satu cara untuk menunjukkan kualitas yang dimiliki oleh bank, dengan tujuan untuk membuat nasabah merasa puas atas kualitas dan jasa yang diberikan bank kepada nasabah. Perbaikan layanan jasa bank saat ini seperti merancang interior menjadi lebih menarik, kenyamanan ruang tunggu, kebersihan lingkungan layanan, kualitas peralatan dan perabotan kantor yang menunjang kecepatan dan kemudahan dalam memberikan layanan terhadap nasabah, serta para karyawan yang bersikap ramah dan berpenampilan rapi. Perbaikan layanan bank tersebut merupakan cara untuk membentuk kepuasaan nasabah yang pada gilirannya loyalitas nasabah makin tinggi serta nasabah tidak mudah berpindah ke bank lain bahkan akan merekomendasi relasinya berhubungan dengan bank tersebut.

Dalam industri jasa seperti perbankan, juga terdapat interaksi yang berupa komunikasi langsung maupun tidak langsung antara karyawan dengan nasabah. Bank memiliki nasabah yang berasal dari berbagai kalangan dan pekerjaan atau profesi, sehingga diperlukan suatu kualitas komunikasi yang baik agar informasi yang diberikan dapat diterima dengan baik pula oleh nasabah. Jadi komunikasi dalam pengertian pragmatis bersifat intensional, mengandung tujuan tertentu yang diawali suatu perencanaan entah komunikasi itu dengan maksud untuk memberi tahu, mengubah sikap, pendapat atau perilaku orang lain (Bahri Djamarah 2014:4). Komunikasi adalah salah satu kunci yang penting dalam suatu hubungan dengan sebuah proses interaksi dan proses nilai, di mana proses tersebut merupakan alat kesuksesan eksekusi yang penting dalam strategi hubungan. Kualitas komunikasi karyawan yang baik akan berdampak pada kepuasan nasabah, karena hanya dengan kualitas komunikasi yang baik, maka setiap informasi yang diberikan oleh karyawan akan dapat diterima dengan baik oleh nasabah sehingga nasabah dapat merasa puas dan kembali ke bank untuk menggunakan layanan tersebut.

\section{KAJIAN PUSTAKA}

\section{Kepuasan}

Kotler dan Keller (2016:153) mendefinisikan Kepuasan adalah perasaan senang atau kecewa seseorang yang timbul setelah membandingkan kinerja yang telah dipersepsikan suatu produk atau jasa (hasil) dengan harapannya. Jika kinerja gagal memenuhi harapannya, maka pelanggan akan merasa tidak puas. Jika kinerja sesuai dengan harapannya, maka pelanggan akan merasa puas. Jika melebihi harapannya, maka pelanggan akan merasa sangat puas atau senang. Menurut Fandy Tjiptono (2016:219) terdapat beberapa metode yang dapat digunakan perusahaan untuk mengukur dan memantau kepuasan pelanggannya dan pelanggan pesaing, yaitu :1) Sistem keluhan dan saran, 2) Survei kepuasan pelanggan, 3) Terpenuhinya harapan pelanggan dan 4) Sikap/keinginan menggunakan produk. 


\section{Loyalitas}

Kotler dan Keller (2016:138) mendefinisikan loyalitas sebagai berikut: Loyalitas pelanggan adalah komitmen yang dipegang secara mendalam untuk membeli atau mendukung kembali produk atau jasa yang di sukai di masa depan, meski pengaruh situasi dan usaha pemasaran berpotensi menyebabkan pelanggan beralih. Pelanggan yang loyal juga akan mencoba untuk membeli lini produk lain yang ditawarkan perusahaan. Selain itu pelanggan yang loyal dapat terlihat dari perilaku mereka yang mendukung produk atau jasa dari suatu perusahaan dengan cara merekomendasikan produk atau jasa tersebut kepada keluarga atau rekannya. Seperti yang diungkapkan oleh Kotler dan Keller (2016:650) pelanggan yang loyal memiliki indikator sebagai berikut: 1) Repeat Purchase, 2) Retention dan 3) Referalls.

\section{Servicescape}

Zeithaml dan Bitner (2013:278) mendefinisikan servicescape sebagai berikut, Lingkungan fisik merupakan semua aspek fasilitas suatu organisasi jasa yang meliputi atribut-atribut eksterior (papan informasi, tempat parkir, pemandangan alam) dan atribut-atribut interior (desain, tata letak, peralatan, dan dekorasi). Semakin lingkungan yang diberikan penyedia jasa berkualitas maka kenyamanan yang dirasakan nasabah akan tinggi, perusahaan juga harus memberikan survei kepuasan kepada nasabah tentang service yang telah diberikan perusahaan agar perusahaan dapat mempertahakan pelayanannya dan membuat nasabah akan semakin puas. Dan dapat membuat nasabah lebih sering menggunakan jasa tersebut, sehingga bisa menimbulkan pembelian berulang atau bahkan nasabah bisa merekomendasikan jasa tersebut ke orang lain. Adapun indikator servicescape menurut Zeithaml dan Bitner (2013:296) sebagai berikut: 1) Ambient conditions, 2) Spatial layout and functionality dan 3) Signs, symbol and artifact.

\section{Kualitas Komunikasi}

Bernard Berelson dan Gary A. Steiner (Mulyana, 2013:68), "Komunikasi: trasnmisi informasi, gagasan, emosi, keterampilan, dan sebagainya dengan menggunakan symbol-simbol, kata-kata, gambar, figut, grafik, dan sebagainya. Tindakan atau proses transmisi itulah yang biasa disebut komunikasi". Komunikasi yang baik dapat menciptakan hubungan jangka panjang antara nasabah dengan bank. Komunikasi akan memudahkan nasabah atau calon nasabah dalam memperoleh informasi dan memilih produk (pelayanan jasa) yang ditawarkan oleh karyawan yang paling sesuai dengan kebutuhan mereka. Jika nasabah mendapat informasi yang mereka butuhkan dengan mudah dan karyawan dapat bersikap terbuka serta memahami apa yang dirasakan nasabah, maka nasabah akan merasa aman dan percaya terhadap kredibilitas bank tersebut. Sehingga nasabah akan terus menggunakan jasa yang diberikan perusahan dan tidak akan berpindah ke perusahaan lain. Bahkan nasabah akan mengajak dan merekomendasikan produk/jasa perusahaan kepada orang lain. Menurut Miftah 
Thoha (2016) beberapa indikator dalam mengukur kualitas komunikasi yaitu 1) Keterbukaan, 2) Empathy, 3) Dukungan, 4) Kepositifan dan 5) Kesamaan.

\section{KERANGKA PENELITIAN}

Penelitian ini menggunakan dua variabel independen yaitu servicescape (X1) dan kualitas komunikasi (X2) serta satu variabel dependen yaitu loyalitas (Y1) dan satu variabel intervening yaitu kepuasan (Y2). Untuk dapat mengetahui alur hubungan antar variabel, maka disusunlah kerangka berpikir sebagai berikut :

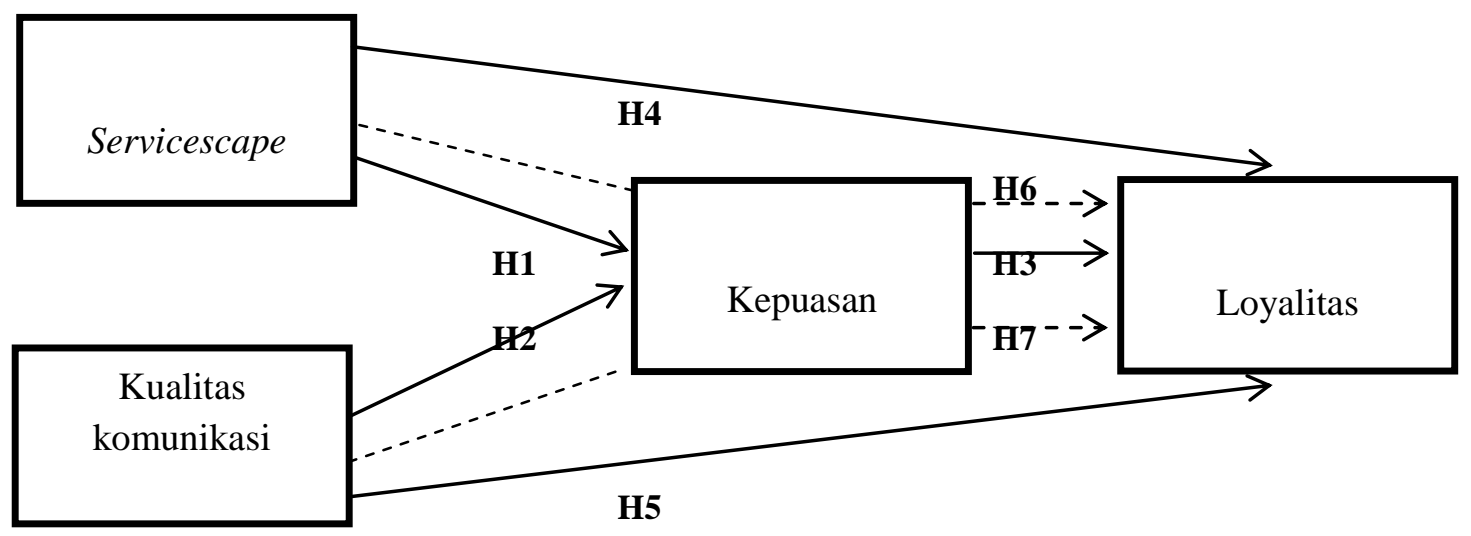

Gambar 1 : Kerangka Pemikiran Teoritis

\section{METODE PENELITIAN}

\section{Jenis dan Sumber Data}

Jenis data dalam penelitian ini menggunakan data primer yang berasal dari obyek penelitian yaitu Bank Tabungan Pensiunan Nasional Cabang Yogyakarta. Data primer diperoleh dari sumber data secara langsung (responden) kepada peneliti melalui penyebaran kuesioner.

\section{Populasi dan Sampel}

Populasi dalam penelitian ini adalah adalah 11.087 nasabah. Metode pemilihan sampel menggunakan metode purposive sampling. Kriteria responden dalam penelitian ini adalah nasabah yang sudah bergabung di Bank BTPN Cabang Yogyakarta lebih dari 1 tahun. Karena jumlah populasi diketahui dengan pasti, maka perhitungan jumlah sampel didasarkan pada rumus formula statistika dengan pendekatan Slovin sehingga diperoleh hasil berjumlah 120 responden. 


\section{Teknik Analisis Data}

\section{Analisis Deskriptif}

Analisis deskriptif dilakukan dengan mengelompokkan data pada masingmasing kategori tersebut, maka dibuat range (interval) dengan rumus sebagai berikut :

$$
\text { int }=\frac{\sum \mathrm{s}_{\max }-\sum \mathrm{s}_{\min }}{\sum_{\mathrm{i}=1}^{\mathrm{n}} \mathrm{k}_{\mathrm{i}}}
$$

Keterangan :

$$
\begin{array}{ll}
\text { int } & =\text { Interval } \\
\sum \mathrm{s}_{\max } & =\text { Skor Total Maksimum } \\
\sum \mathrm{S}_{\min } & =\text { Skor Total Minimum } \\
\sum_{\mathrm{i}=1}^{\mathrm{n}} \mathrm{k}_{\mathrm{i}} & =\text { Jumlah Kriteria }
\end{array}
$$

\section{Analisis Inferensial}

\begin{tabular}{|c|c|}
\hline Uji Model & Output \\
\hline \multirow[t]{3}{*}{ Uji Indikator } & $\begin{array}{l}\text { Convergent Validity dinilai berdasarkan korelasi antara item score atau } \\
\text { component score. Indikator individu dianggap valid jika memiliki nilai } \\
\text { korelasi diatas } 0,50 \text {. Apabila ada indikator yang tidak memenuhi syarat } \\
\text { ini maka harus dihilangkan. }\end{array}$ \\
\hline & $\begin{array}{l}\text { Discriminant Validity pada nilai AVE lebih tingi daripada nilai korelasi } \\
\text { di antara variabel laten, maka discriminant validity dapat dianggap } \\
\text { tercapai. Discriminant validity dapat dikatakan tercapai apabila nilai } \\
\text { AVE lebih besar dari } 0,5 \text {. }\end{array}$ \\
\hline & $\begin{array}{l}\text { Composite Reliability dapat dikatakan baik apabila nilai composite } \\
\text { reliability lebih besar dari } 0,6 \text {. }\end{array}$ \\
\hline Uji Hipotesis & $\begin{array}{l}\text { Pengujian terhadap model structural yang dilakukan dengan melikhat } \\
\text { nilai R-square sebagai uji goodness of fit model. Selain itu juga dilakukan } \\
\text { uji signifikansi pengaruh antar konstruk dengan melihat nilai koefisien } \\
\text { parameter dan nilai signifikansi statistiknya }\end{array}$ \\
\hline
\end{tabular}

Analisis inferensial dalam penelitian ini menggunakan metode Structural Equation Modeling (SEM) dengan menggunakan alat analisis Partial Least Square (PLS) yaitu SEM berbasis variance, dengan software SmartPLS. Tahap pengujian PLS sebagai berikut:

Tabel 1: Kriteria Penilaian PLS

Bisman (Bisnis \& Manajemen): The Journal Of Business and Management 


\section{Uji Sobel Test}

Uji sobel Test adalah Untuk mengetahui seberapa besar peran variabel intervening pada penelitian. Sobel test yaitu suatu langkah pengujian untuk mengetahui apakah pengaruh variabel independen yang melalui variabel intervening atau variabel mediasi secara signifikan mampu menjadi mediator dalam pengaruh tersebut. Kriteria pengujian: Apabila Zscore > Ztabel maka membuktikan bahwa variabel mediasi mampu berperan menjadi mediator antara variabel independen dengan variabel dependen.

\section{PEMBAHASAN DAN HASIL}

\section{Hasil Uji Analisis Inferensial}

Uji Inferensial pada penelitian ini metode yang digunakan yaitu dengan Structural Equation Modeling (SEM) dengan menggunakan alat analisis Partial Least Square (PLS) yaitu SEM berbasis variance, dengan software SmartPLS dengan hasil pengujian sebagai berikut :

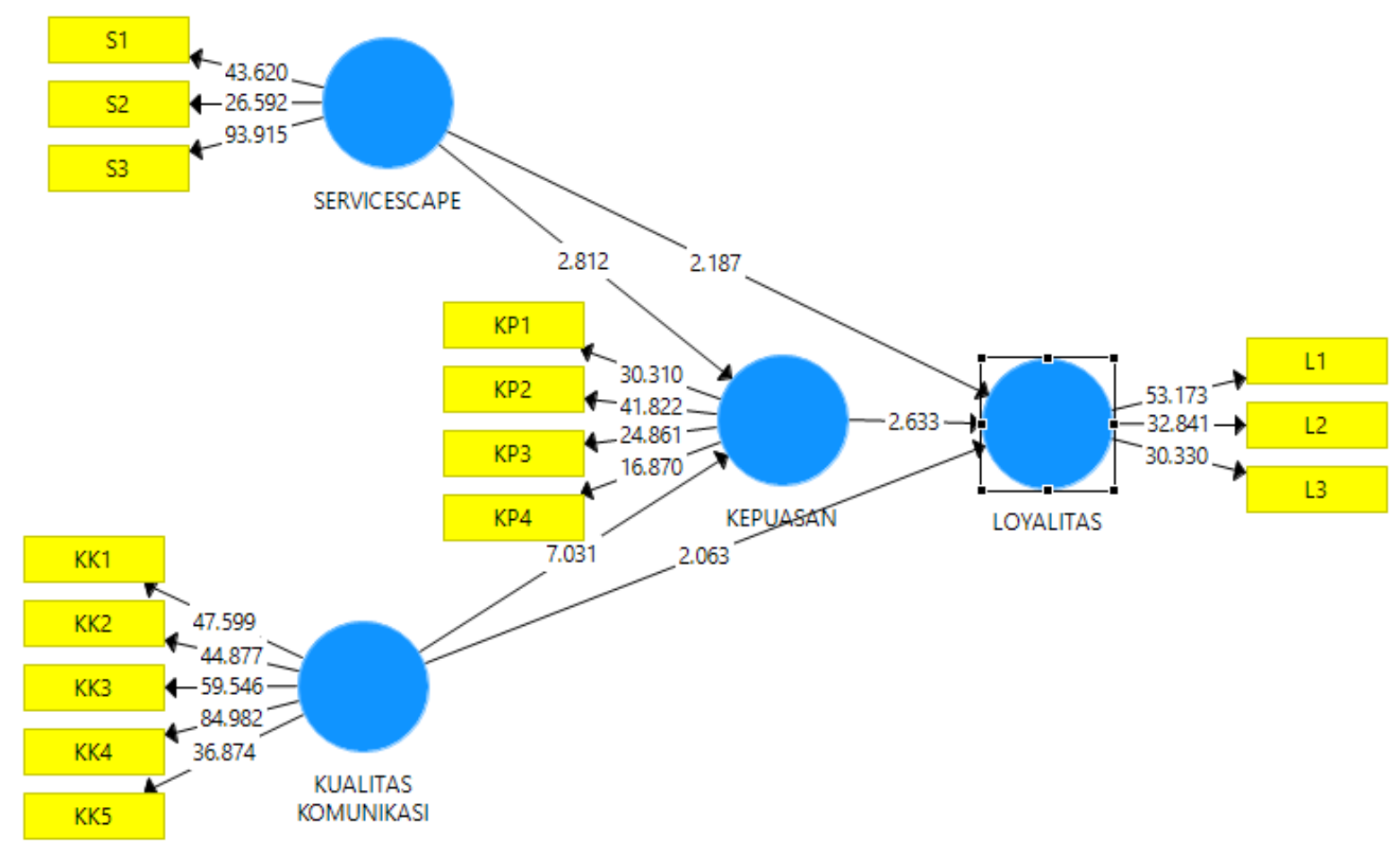

Gambar 2 : Hasil Akhir Kalkulasi SmartPLS

Berdasarkan hasil SmartPLS tahap akhir, semua indikator memiliki nilai korelasi diatas 0,50 sehingga semua indikator dianggap valid. Terpenuhinya syarat pertama berdampak terhadap nilai AVE variabel laten dimana seluruhnya sudah 
memiliki nilai di atas 0,50 . Seluruh variabel juga sudah memenuhi syarat realibiltas dengan nilai diatas 0,60 , sehingga telah memenuhi syarat ke dua validasi model dan dapat dilanjutkan ke tahap penilaian outer model.

\section{Hasil Uji Hipotesis} berikut:

Analisis hipotesis pada hasil penelitian ini dapat dipaparkan sebagai

Berdasarkan tabel diperoleh hasil berikut : 1) Nilai pengujian hipotesis H1 nilai koefisien parameter 0,262, ini menunjukkan bahwa Servicescape (X1) memiliki pengaruh positif terhadap Kepuasan (Y1). Sedangkan P-Value diperoleh nilai $0,005(<0,05)$. Ini menunjukkan bahwa Servicescape (X1) berpengaruh signifikan terhadap Kepuasan (Y1). 2) Nilai pengujian hipotesis H2 nilai koefisien parameter 0,636, ini menunjukkan bahwa Kualitas Komunikasi (X2) memiliki pengaruh positif terhadap Kepuasan (Y1). Sedangkan P-Value diperoleh nilai 0,000 ( $<0,05)$, ini menunjukkan bahwa Kualitas Komunikasi (X2) berpengaruh signifikan terhadap Kepuasan (Y1). 3) Nilai pengujian hipotesis H3 nilai koefisien parameter 0,365, ini menunjukkan bahwa Kepuasan (Y1) memiliki pengaruh positif terhadap Loyalitas (Y2). Sedangkan P-Value diperoleh nilai 0,040 ( <0,05 ), ini menunjukkan bahwa Kepuasan (Y1) berpengaruh signifikan terhadap Loyalitas (Y2). 4) Nilai pengujian hipotesis H4 nilai koefisien parameter 0,285, ini menunjukkan bahwa Servicescape (X1) memiliki pengaruh positif terhadap Loyalitas (Y2). Sedangkan P-Value diperoleh nilai 0,029 ( $<0,05)$ ini menunjukkan bahwa Servicescape (X1) berpengaruh signifikan terhadap Loyalitas (Y2). 5) Nilai pengujian hipotesis H5 nilai koefisien parameter 0,297, ini menunjukkan bahwa Kualitas Komunikasi (X2) memiliki pengaruh positif terhadap Loyalitas (Y2). Sedangkan P-Value diperoleh nilai 0,009 ( $<0,05)$, ini menunjukkan bahwa Kualitas Komunikasi (X2) berpengaruh signifikan terhadap Loyalitas (Y2). 6) Nilai pengujian hipotesis H6 nilai koefisien parameter 0,096, ini menunjukkan bahwa Servicescape (X1) memiliki pengaruh positif terhadap Kepuasan (Y1) melalui Loyalitas (Y2). Sedangkan P-Value diperoleh nilai 0,047 ( $<0,05$ ), ini menunjukkan bahwa Servicescape (X1) berpengaruh signifikan terhadap Kepuasan (Y1) melalui Loyalitas (Y2). 7) Nilai pengujian hipotesis H6 nilai koefisien parameter 0,232, ini menunjukkan bahwa Kualitas Komunikasi (X2) memiliki pengaruh positif terhadap Kepuasan (Y1) melalui Loyalitas (Y2). Sedangkan P-Value diperoleh nilai 0,021 ( <0,05 ), ini menunjukkan bahwa Kualitas Komunikasi (X2) berpengaruh signifikan terhadap Kepuasan (Y1) melalui Loyalitas (Y2).

\section{Hasil Uji Sobel Test}

Penelitian ini dilakukan uji sobel tes dengan hasil seperti pada tabel berikut: 
Tabel 2 : Hasil Uji Sobel Test

\begin{tabular}{lccl}
\hline \multicolumn{1}{c}{ Variabel } & Z skor & Z tabel & Kesimpulan \\
\hline Servicescape $(\mathbf{X 1})$ & 2,07 & 1,96 & Intervening berperan \\
Kualitas Komunikasi (X2) & 3,19 & 1,96 & Intervening berperan \\
\hline
\end{tabular}

Berdasarkan tabel diatas dapat dilihat bahwa hasil sobel tes untuk variabel Servicescape memiliki nilai Z skor 2,07 > dari Z tabel 1,96. Sehingga dapat disimpulkan bahwa variabel intervening Kepuasan memiliki peran dalam hubungan antara variabel Servicescape dan variabel Loyalitas.

Sedangkan pada variabel Kualitas Komunikasi memiliki nilai Z skor 3,19 $>$ dari Z tabel 1,96. Sehingga dapat disimpulkan bahwa variabel intervening Kepuasan memiliki peran dalam hubungan antara variabel Kualitas Komunikasi dengan variabel Loyalitas.

\section{KESIMPULAN DAN SARAN}

\section{Kesimpulan}

Berdasarkan hasil penelitian, dapat diambil kesimpulan-kesimpulan yang berkaitan dengan Pengaruh Servicescape dan Kualitas Komunikasi terhadap Loyalitas Nasabah melalui Kepuasan Nasabah sebagai Variabel Intervening (studi pada nasabah Bank Tabungan Pensiunan Nasional KC Yogyakarta) sebagai berikut :

1) Hasil uji hipotesis H1 membuktikan bahwa Servicescape berpengaruh positif terhadap Kepuasan. Dengan demikian dapat disimpulkan bahwa hipotesis yang menyatakan bahwa Servicescape berpengaruh positif dan signifikan terhadap Kepuasan terbukti.

2) Hasil uji hipotesis $\mathrm{H} 2$ membuktikan bahwa Kualitas Komunikasi berpengaruh positif terhadap Kepuasan Dengan demikian dapat disimpulkan bahwa hipotesis yang menyatakan bahwa Kualitas Komunikasi berpengaruh positif dan signifikan terhadap Kepuasan terbukti.

3) Hasil uji hipotesis H3 membuktikan bahwa Kepuasan berpengaruh positif terhadap Loyalitas. Dengan demikian dapat disimpulkan bahwa hipotesis yang menyatakan bahwa Kepuasan berpengaruh positif dan signifikan terhadap Loyalitas terbukti.

4) Hasil uji hipotesis H4 membuktikan bahwa Servicescape berpengaruh positif terhadap Loyalitas. Dengan demikian dapat disimpulkan bahwa hipotesis yang menyatakan bahwa Servicescape berpengaruh positif dan signifikan terhadap Loyalitas terbukti.

5) Hasil uji hipotesis H5 membuktikan bahwa Kualitas Komunikasi berpengaruh positif terhadap Loyalitas. Dengan demikian dapat disimpulkan bahwa 
hipotesis yang menyatakan bahwa Kualitas Komunikasi berpengaruh positif dan signifikan terhadap Loyalitas terbukti.

6) Hasil uji hipotesis H6 membuktikan bahwa Servicescape berpengaruh positif terhadap Loyalitas melalui Kepuasan. Dengan demikian dapat disimpulkan bahwa hipotesis yang menyatakan bahwa Servicescape berpengaruh positif dan signifikan terhadap Loyalitas melalui Kepuasan terbukti.

7) Hasil uji hipotesis $\mathrm{H} 7$ membuktikan bahwa Kualitas Komunikasi berpengaruh positif terhadap Loyalitas melalui Kepuasan. Dengan demikian dapat disimpulkan bahwa hipotesis yang menyatakan bahwa Kualitas Komunikasi berpengaruh positif dan signifikan terhadap Loyalitas melalui Kepuasan terbukti.

\section{Saran}

Berdasarkan hasil penelitian yang telah dijelaskan sebelumnya, maka saran yang dapat diberikan yaitu sebagai berikut:

1) Pihak Bank BTPN perlu meningkatkan variabel loyalitas terutama pada item menjadikan Bank BTPN pilihan pertama bila ingin menggunakan jasa perbankan, nasabah belum sepenuhnya yakin untuk memprioritaskan produk/jasa Bank BTPN karena masih tertarik produk/jasa dari bank lain. Untuk itu perlu usaha dari pihak Bank BTPN untuk selalu mengupgrade fiturfitur produknya agar dapat dipergunakan bertransaksi dalam segala sesuatu yang berhubungan dengan transaksi online.

2) Pihak Bank BTPN perlu meningkatkan variabel kepuasan terutama pada item tertarik menggunakan produk Bank BTPN setelah melihat iklan di sosial media, hal ini terjadi karena promosi produk/jasa dari Bank BTPN di sosial media belum terlalu booming. Pada saat ini promosi di sosial media sangat menguntungkan karena setiap orang dapat mengakses sosial media dengan mudah, sehingga ini peluang bagi pihak Bank BTPN menawarkan produk/jasanya melalui sosial media untuk memberitahu fitur-fitur terbaru tabungan Bank BTPN kepada nasabahnya dan juga menarik calon nasabah baru.

3) Bagi peneliti selanjutnya diharapkan untuk menambah jumlah sampel penelitian dengan memperluas obyek penelitian tidak hanya memfokuskan pada satu cabang saja. Sehingga akan memperoleh hasil yang lebih sempurna. 


\section{DAFTAR PUSTAKA}

Absah, Y. et al. (2020) 'The Influence Of Servicescape , Brand Image And Customer Relationship Management On Customer Satisfaction And Customer Loyalty At Fast Food In Medan City', 29(8), pp. 33-45.

Abtin, A. and Pouramiri, M. (2016) 'The impact of relationship marketing on customer loyalty enhancement ( Case study: Kerman Iran insurance company )', 3, pp. 41-49.

Aka, D. O., Kehinde, O. J. and Ogunnaike, O. O. (2016) 'Relationship Marketing and Customer Satisfaction: A Conceptual Perspective', Binus Business Review, 7(2), p. 185. doi: 10.21512/bbr.v7i2.1502.

Azza, T. B., Dahmane, B. and Norchene, M. (2017) 'Social and Physical Aspects of the Service Encounter: Effects on Trust and Customer Loyalty to the Service Provider', 5(1), pp. 1-10. doi: 10.13189/aeb.2017.050101.

Brown, B. R. (2018) 'The Dimensions of Pet-Owner Loyalty and the Relationship with Communication, Trust, Commitment and Perceived Value', (September). doi: 10.3390/vetsci5040095.

Chung, Ki-Han dan Ji-Eun Yu, Myeong-Guk Choi, Jae-Ik Shin. 2015. The Effects of CRS on Customer Satifaction and Loyalty in China: The Moderating Role of Corporate Image, Journal of Economics, Business and Management, Vol. 3, No. 5, p542-547.

Fandy Tjiptono dan Gregorius chandra. 2016. Service, Quality \& satisfaction. Yogyakarta. Andi.

Febrian (2016) 'Pengaruh Servicescape Dan Kualitas Pelayanan Customer Service Terhadap Kepuasan Nasabah Pada Pt. Bank Bni (Persero, Tbk) Cabang Manado', Jurnal Berkala Ilmiah Efisiensi, 16(4), pp. 203-215.

Hakim, A. and Asy, A. (2017) 'The Effect Relationship Marketing Dimension on Customer Loyalty of Muslim Entrepreneurs', 19(8), pp. 1-13. doi: 10.9790/487X-1908010113.

Istiqomah, A. (2017) 'Pengaruh Dimensi Relationship Marketing Terhadap Kepuasan Dan Loyalitas Nasabah', Jurnal Ekonomi Bisnis, 18(1), pp. 2839.

Jumaev, M., M., P. D. D. K. and Hanaysha, J. R. M. (2017) 'Impact Of Relationship Marketing On Customer Loyalty In The Banking Sector', Far East Journal of Psychology and Business, 6 No 3 Pap(Hirschman 1970), pp. 36-55. Available at: http://ideas.repec.org/a/fej/articl/v6cy2012i4p36-55.html. 
KAMAU, B. N. (2017) 'INFLUENCE OF SERVICESCAPE ON CUSTOMER SATISFACTION IN RESTAURANTS WITHIN CLASSIFIED HOTELS IN NAIROBI COUNTY, KENYA', (July).

Kartika, C., Adam, alif dio and Trisna, E. (2019) 'Pengaruh Servicescape, Kualitas Komunikasi Pelayanan dan Kepercayaan Nasabah terhadap Kepuasan dan Dampaknya pada Relationship Intention Nasabah Bank Syariah di Surabaya', e-Journal Unitomo, 3(1), pp. 43-60.

Kim, M. et al. (2017) 'From servicescape to loyalty in the medical tourism industry: A medical clinic's service perspective', Inquiry (United States), 54. doi: 10.1177/0046958017746546.

Marso, Idris, R. and Widyarini, L. A. (2020) 'Influence of the Upscale Café Servicescape on Satisfaction and Loyalty Intention', 115(Insyma), pp. 312-315. doi: 10.2991/aebmr.k.200127.064.

Massey, J. E. and Raduzzi, A. (2018) 'Customer Satisfaction \& Brand Loyalty in the Fast', (July), pp. 34-40.

Munandar, T. (2018) 'Analisis Pengaruh Relationship Marketing terhadap Loyalitas Nasabah dengan Kepuasan Nasabah sebagai Variabel Intervening di BNI Syariah Kantor Cabang Yogyakarta'.

Putra, R. and Ardiani, W. (2018) 'Effect of Communication Process on Customer Satisfaction in Improving Customer's Retention', Academic Journal of Economic Studies, 4(3), pp. 87-95.

PUTRI, A. R. (2018) 'ANALISIS PENGARUH LINGKUNGAN FISIK, KUALITAS PELAYANAN, DAN PERSEPSI HARGA TERHADAP LOYALITAS KONSUMEN DENGAN KEPUASAN KONSUMEN SEBAGAI VARIABEL INTERVENING (Studi Empiris di Angkringan Modern Playground Solo)'.

Putri, E. N. (2018) 'Loyalitas Pelanggan ( Survei pada Pelanggan Toko Oen Malang )', Jurnal Administrasi Bisnis, 62(1), pp. 63-72.

Qasem, A. (2019) 'The Impact of Service Quality and Communication in Developing Customer Loyalty: The Mediating Effect of Customer Satisfaction', 25(4), pp. 137-173.

Rahimi Koloor, H. (2015) 'Developing a communication model between banking services quality via mediating variables of quality of relationship with customers and satisfaction with customer loyalty: A case study of Tejarat Bank', International Journal of Organizational Leadership, 4(1), pp. 8699. doi: 10.33844/ijol.2015.60442.

Rai, A. K. (2020) 'Investigating the influence of servicescape on customer loyalty at a fine - dining restaurants in Jaipur', (2019), pp. 1-9. 
Ruswanti, E. and Lestari, W. P. (2016) 'The Effect of Relationship Marketing towards Customers' Loyalty Mediated by Relationship Quality (Case Study in Priority Bank in Niaga)', DeReMa (Development Research of Management): Jurnal Manajemen, 11(2), p. 191. doi: 10.19166/derema.v11i2.230.

Sadiartha, A. A. N. G. (2018) 'Research in Business and Social Science Organizational Culture, Communication Leadership Style on Job Satisfaction and', 7(4), pp. 1-9.

Sharma, P. and Lampley, J. (2015) 'Organizational Communication : Perceptions of Staff Members ' Level of Communication Satisfaction and Job Satisfaction'.

Situmorang, S. H. (2018) 'Influence Of Servicescape, Customer Satisfaction, WOM, and Social Media to Consumer Loyalty (study case bali beach)', 46(Ebic 2017), pp. 403-408. doi: 10.2991/ebic-17.2018.62.

Situmorang, W. R. and Rini, E. S. (2020) 'The Effect of Social Media , Servicescape and Customer Experience on Revisit Intention with The Visitor Satisfaction as an Intervening Variables in The Tree House on Tourism Habitat Pamah Semelir Langkat Regency', 7(February), pp. 7984.

Sulartiningrum, S. et al. (2016) 'The Analysis of Servicescape and Customer Loyalty in Bale Raos Ethnic Restaurant in Yogyakarta', 18(7), pp. 19-24. doi: 10.9790/487X-1807031924.

Syaifullah (2018) 'Pengaruh Kepercayaan Dan Komunikasi Terhadap Loyalitas Pelanggan Pada Pt Spectrum Lintas Service Di Kota Batam', Jurnal Ilmiah Manajemen Universitas Putera Batam, 6(1), p. 231201.

Turker, N. (2019) 'Measuring the Effect of Restaurant Servicescapes on Customer Loyalty', 6(November 2019), pp. 255-270.

Ula, R. and Fauzi, A. (2019) 'the Role of Free Wireless Fidelity ( Wi-Fi ) Service , Food Quality, and Servicescape Toward Customer Satisfaction', Asian Journal of Social Science Research, 2(2).

Yuliyasti, R., Masdupi, E. and Abror, A. (2018) 'The Relationship between Brand Experience, Customer Satisfaction and Customer Loyalty: Brand Trust as The Intervening Variable', 57(Piceeba), pp. 366-374. doi: 10.2991/piceeba-18.2018.68.

Zeithaml, V.A., M.J. Bitner, D.D. Gremler. 2013. Services Marketing: Integrating Customer Focus Across the Firm 6th ed. Mc. Grwa-Hill. Boston. 